\title{
Sacrifice of Poultry Birds by Tribals of Koraput District of Odisha, India
}

\author{
J. Mishra ${ }^{1}$, B. C. Das ${ }^{1 *}$ and K. K. Sardar ${ }^{2}$ \\ ${ }^{1}$ Department of Veterinary and Animal Husbandry Extension, ${ }^{2}$ Department of Pharmacology \\ \& Toxicology, College of Veterinary Science \& Animal Husbandry, Odisha University of \\ Agriculture and Technology, Bhubaneswar, Odisha, India \\ *Corresponding author
}

\begin{abstract}
A B S T R A C T
Sacrifice of animals and birds for socio-cultural and religious events have long been an indispensable part of human civilization. The present exploratory investigation was directed in this direction to study poultry sacrifices among the tribal people of Koraput district-a tribal dominated area of Southern Odisha. Six tribal people who facilitate religious practices for the tribal people were taken as cases for this study. They were selected on the basis of having long duration of practising the rituals for benefit of the community. To maintain the sanctity and efficacy of the sample, care was taken to cover people of different villages with their own unique effect to the generally accepted practices. The study culminated in the conclusion that, the ancient belief still has its palpable presence among the tribal people of Koraput, even after the effect of modern outlook and rapid development.
\end{abstract}

\section{Introduction}

Every religion nurtures the traditional rituals as a mark of its identity. Remembering one's own roots is signified by the old practices. This is a sign of belongingness to a certain group or community. Tribal world has long been glued to their religious beliefs and practices which have been inherited from their forefathers. These people strongly believe that nature, spirits and human beings are not separate entities. They co-exist as a singular organism with subtle level of dependence. So, the primitive people show reverence towards nature and unseen spirits. In Sikkim, Lepcha tribes of Buddhist philosophy, believe that supernatural beings reside in every mountain, hilltop, lake and river. They worship the pious spirits in a way to show their gratitude for their blessings. There is a common belief which says red offerings such as blood and meat are preferred 
by local deities (Marlene Erschbamer, 2019). Sacrificial rituals are intended to show loyalty to the supernatural being and there is an intention to worship, calm or tame the beings as the context demands (Sethy, 2007).

In the district of Koraput, the share of scheduled tribes is more than $50 \%$ of the total population. They have a wellknit societal order and a unique cultural dimension. The 2011 census indicates a tribal share of more than $50 \%$ in the total population in the district. Bhumia, Bhatra, Gond, Koya, Paraja, Kondh are the important tribes of the district. They observe ceremonies of child birth, marriage, death, sowing and harvesting of crops at family and community level with sacrifices of indigenous birds. Very frequently the community level ceremonies they perform include Chaiti Parab, Pus Parab, Ghanta Parab, Sim (bean) Parab, Aam (Mango)Parab, Bhairabi Jatra, Nuakhai, Dhan-Nua Dialli and Manda. They worship the unseen God and Goddess with drawings of "Muruja and Jhoti" in tantric design for blessing.

It is fascinating to learn that chicken occupies a very special place in the tribal cultures. The rooster symbolizes the male energy and is used for both breaking of dawn (knowledge/good) and the waning of darkness (ignorance/evil). Most of the worships have been done for material gain. Sacrificial offering is a part of several worships. Animals $\&$ birds are chosen for sacrificial purposes by the tribe of Koraput depending on the largeness of the desire and the prevailing star of the season.

\section{Materials and Methods}

The study was conducted in Semeliguda block of Korpaut district which is dominated by sacrificial practices followed by the traditional worshipers. Six prominent practitioners from five Gram Panchayats were identified with the help of local paravets and traditional healers and they were interviewed personally at their doorsteps with the help of semi-structured interview schedule to find out the purposes of the bird sacrifices and the importance of such types of practices. Utmost care was taken to persuade them to express themselves exhaustively on the topic of study. Most of the time informal discussion was made to make them ease in revealing the information. Help of local youth with some education and exposure were obtained at the site to facilitate understanding of the questions by the respondents which were put by the investigator. The qualitative data collected were analysed to list the sacrificial practices followed by the tribe. The photographs, name and address of the spiritual practitioners contacted for this case study are presented below.

\section{Results and Discussion}

The study revealed that even after being subjected to effects of modernisation, the core value of practices remains the same. But the exercise and the materials required for rituals are gradually changing to give space to urban influence. The views expressed by the spiritual priest amply indicate that there is existence of practice of bird sacrifice in the tribal community. However, in different sects, there are differences of belief. The findings of the poultry sacrifice compiled in this study are discussed under four broad categories as mentioned below.

1. Life- from birth to death

2. Agriculture

3. Health

4. occult purposes

\section{Life -from birth to death}

Birth of a child is a matter of great happiness in the tribal family. Celebration of this occasion takes place on the $7^{\text {th }}$ or $11^{\text {th }}$ day of 
birth. At the front veranda of the house the mother sits cross legged with the baby on her lap. The disari performs puja reciting the sacred verses and pray the lord to shower the baby with his blessings which would make him healthy and prosperous in his/her life. The sacrifice of a bird is usually done in the end. It is regarded as the" Prasad". The puja is followed by a feast involving the relatives of the family and the village people.

Attaining puberty is another important aspect of female, where they reach child bearing capacity. A new life starts and the respect of the society for the young lady is established in a celebration. The selection of bird is done from several conditions, i.e., position of different planets at the time of first bleeding, the direction to which the girl was facing during the time, etc. For 10 days, the girl has to reside in a separate temporary thatched house without being seen by the villagers. Only females are allowed to enter into the house for giving food or anything of urgency. The girl has to complete her daily chores before the sunrise. On the $11^{\text {th }}$ day, ladies of the village take her to the stream or river for bathing, early in the morning. They stay there till $2 \mathrm{pm}$ and then come back to the village. The spiritual practitioner performs the pooja with flowers, fruits, incense sticks, etc. and in the end sacrifices a bird of black colour. Thereafter, the girl can enter her parental house. This occasion culminates in a grand feast in the village. In some sects of the study area, maturity celebration also takes place in the $7^{\text {th }} / 9^{\text {th }}$ day.

Death of a member of the family aggrieves the other members. The dead body is incinerated in the graveyard, which is situated a little away from human habitation. On the $3^{\text {rd }}$ day, the disari performs a ritual in the deceased person's house in presence of only the family members. At the end, a black hen is sacrificed to pacify the soul of the departed member. Only after this occasion, the family members are allowed to mingle with the society.

The sacrifice of animals - most commonly goats and chickens- forms the climax of many festivals of our country, especially in rural areas. The animals and bird's sacrifices are intimately linked to village social order and prosperity. Both of these are prerequisites if festivals are to be performed on the scale needed to satisfy the notoriously demanding village goddesses, whose satisfaction is in turn a precondition for the continuation of order and prosperity in the year ahead. What is more, such goddesses also bestow (or withhold) human health, fertility and the well-being of all local households and inhabitants. In other words, the stakes at such festivals are very high, and the tension throughout, lest anything should anger or disappoint the goddess, is palpable, as is the sense of relief once the event has been successfully carried to completion (Anthony Good, 2015; Kerketta, 2018).

\section{Agriculture}

It was observed in the study areas that in the month of Vaisakha, the owner of the land either alone or accompanied by the spiritual practitioner, goes to the field before ploughing of the land and perform apoojaby offering with fruits, flowers and eggs to get the God's blessing for a good harvest. The pooja is of short duration of less than 30 minutes and at the end a bird of a white/ red colour is sacrificed. Similarly, on the eve of a good crop, gratitude is conveyed in the same manner at the ground, where the harvest is kept before storage. In tribal locality, people from many different ethnic groups come to consult with the god within the shrine. They bring chickens, goats, sheep, donkeys, cows, and even dogs to sacrifice - offerings to curry favor in their search for fertility, stability, 
prosperity, and security in life. Others sacrifice to make amends for evil acts and to reverse the negative consequences of $\sin$ or curse. The spirits in the shrines are believed to feed off the life-blood of animals, so requests made for help and atonement must be accompanied by sacrifice.

\section{Health}

The tribals of the study area predominantly believe that the bad health condition of self and their family member is due to the curse of evil power. They perform various rituals and pooja to specify the bad effects of evil power on them. They offer animals and birds for spiritual intervention to get rid of some ailments. It is observed that to control diarrhoea in village, a black cock is beheaded by the disari with prayer for kindness of the village deity. The common beliefs, customs and practices connected with health and disease have found to be intimately related with the treatment of disease. The health problems of rural especially of the tribals need special attention because the tribal people have distinctive health problem, which are mainly governed by their traditional beliefs, practices and ecological conditions. Some tribal groups still believe that a disease is always caused by hostile spirits or by the breach of some taboo (Pradhan, 2016).

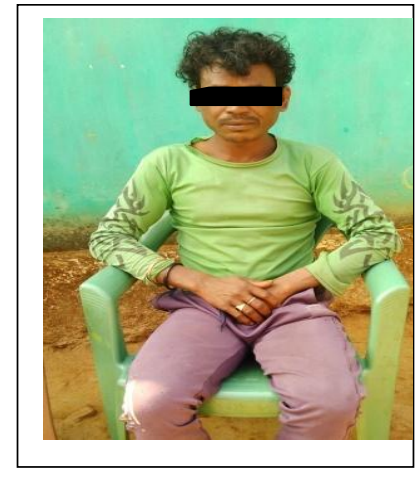

SomanathMuduli Village :Balipeta Aadhaar No 256533

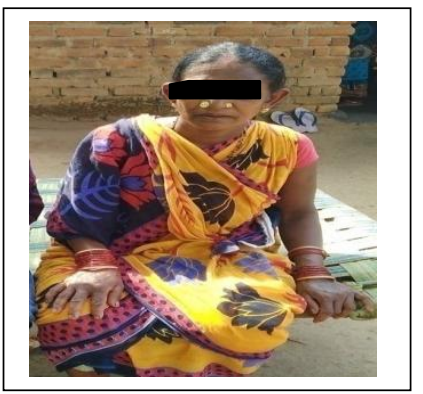

BatiGallori

Village - MajhiMangara

Aaadhaar No:

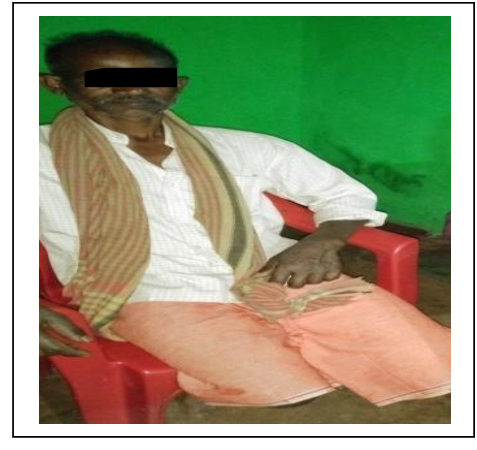

Raghunath Gouda

Village: Gopalput

Aadhaar No:

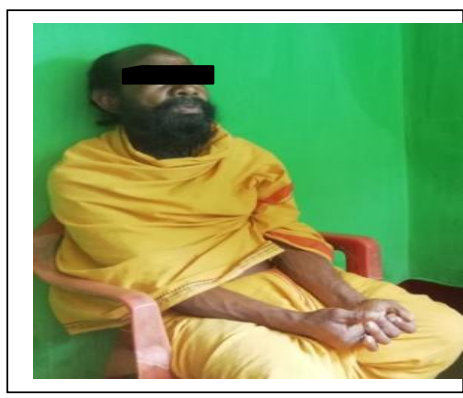

LachhmanJani

Village- Khariguda

Aaadhaar No

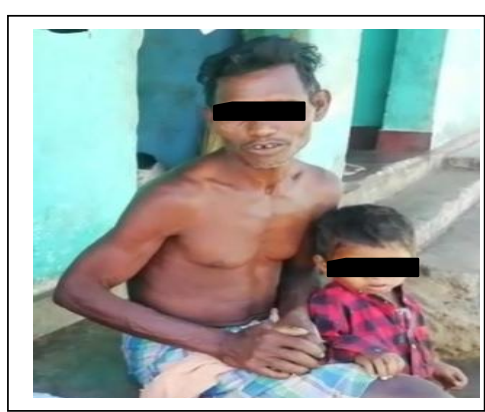

AshuSaunta

Village :Padampur

Aadhaar No: 505915

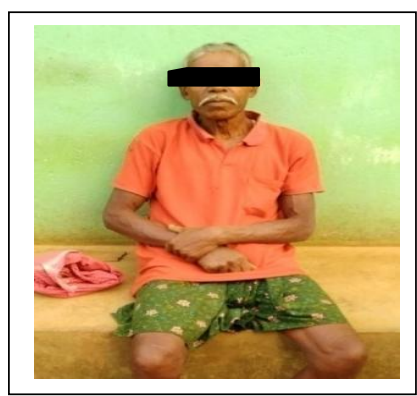

BuduHantalaVillageDayanidhiguda

Aaadhar No: 07626
Tribes are relatively isolated and autonomous groups. The existence of own cultural and medical system is one of the important features of a tribal society. The tribal social 
structure has its own structural and ethnic specificity and the diseases that inflict upon the tribal people are likewise specific to the attribute of their social structure. Moreover, the knowledge of disease, their classification and etiology are constituents of their cultural system and they develop methods and ways of curing the diseases. However, contrary to the vast range of eco-cultural distribution and differences, there are only a few studies on tribals dealing with health, disease and treatment. Tribal health maintenance system is attached with a lot of complexity intertwined with socio-cultural beliefs and practices (Casal, 2003 and Copemen, 2008).

\section{Occult purposes}

The tribes of the study areas have their own blind belief that the behavioural changes, constant loss at work, chronic illnesses, childless, etc. of an individual are due to the effect of evil spirit. The local disari is thought to be competent enough to identify if a person is affected by an evil spirit and he is also capable of removing the evil spirit. Normally, disari perform the rituals after $5 \mathrm{pm}$ in the house of the affected person. In the function puffed rice, molasses and fruits, are used and a black cock is sacrificed in presence of the members of the family to satisfy the evil spirit.

The cause of illness and healing system are found to be associated with the magicoreligious beliefs and the factors like age, sex, education of the patient are also associated with illness. Types of illness, severity of diseases, health care facility, belief regarding the cause of diseases and previous experiences affects selection of different ways of treatment and the villager's responses towards illness behaviour is guided and conditioned by their culture (Pradhan, 2016)

Traditional health care systems have been prevalent in every country since the beginning of the civilization in one form or other based on medicinal herbs, roots and tubers and healing practices based on ayurvedic, unani, sidh as well as natural cure and yoga system. The tribal people or the indigenous people living closest to nature are influenced more by socio-cultural and environmental dimensions in their healing practices. Tribal belief relates to sickness as well as death and ill health to the curse or good will of the deities worshipped by the concerned tribes, appeasement of the God as well as destruction of evil spirits forms a major part of psychosomatic healing or health care system (Srinivasn, 2010).

In conclusion, adherence to the one's own roots exudes the sense of belongingness to the source of creation. In spite of the incessant race for modernisation, in the form of better standard of health and wellness, the tribal people of Koraput district have not forgotten the essence of age old belief system of their forefathers. The study revealed how the people have an emotional bondage to their cultural traditions.

They still believe the triviality of their existence, unless nature and the supernatural beings lead their path with grace. Thus, as a form of appeasement or a sense of gratitude propels them to follow the sacrificial rituals with a sense of complete oneness with the almighty. Finally, it may be suggested that adequate communication facilities should be developed and health centre should be established near to their village with appropriate health awareness programmes. Proper education and mobile health unit should be introduced to take care of the tribal community.

\section{References}

Casal, Paula., 2003. 'Is multiculturalism bad 
for animals?' The Journal of Political Philosophy 11(1):1-22

Copeman, Jacob., 2008. 'Violence, nonviolence and blood donation in India.' Journal of the Royal Anthropological Institute (N.S.) 14:278-96

Erschbamer, M., 2019.Taming of supernatural entities and animal sacrifice. The synthesis of Tibetan Buddhism and local shamanistic traditions in Northern Sikkim (India) [Online], 50. Electronic version.

URL:http://journals.openedition.org/em scat $/ 3915$

Kerketta, V. K. 2018. The Santals' Belief System: An indication to their deeper dimension. International Journal of Engineering Development and Research. 6(1), 2018.

Pradhan, 2016. Health and Health Seeking Behaviour Among the Tribals: A Case Study in Sundargarh District of Odisha. MA Dissertation in Development studies. National institute of Technology. Rourkela. Odisha.

Sethy, B., 2007 Backyard Poultry in Orissa, Odisha Review, January 2007.

Srinivasan, Krithika., 2010. 'The social science imagination in India: deconstructing boundaries and redefining limits.' Sociological Bulletin 59(1): 22-45.

\section{How to cite this article:}

Mishra, J., B. C. Das and Sardar, K. K. 2020. Sacrifice of Poultry Birds by Tribals of Koraput District of Odisha, India. Int.J.Curr.Microbiol.App.Sci. 9(03): 2153-2158.

doi: https://doi.org/10.20546/ijcmas.2020.903.246 